\title{
In-situ resource utilization-feasibility of the use of lunar soil to create structures on the moon via sintering based additive manufacturing technology
}

\begin{abstract}
The feasibility of creation of structures on the Moon using lunar soil as in-situ resource and sintering additive manufacturing technologies is discussed. The use of sintering technologies for additive manufacturing and construction using lunar regolith has already been demonstrated. However, an important point of attention for applying such a process under lunar conditions is the generation of volatiles during heating of the solid particles to the sintering temperature and the possible pyrolysis of the material at temperatures higher than the temperatures required for sintering. The analysis of the available data shows, that the production of constructive elements out of regolith with a guaranteed mechanical performance is feasible by maintaining a precisely tuned process controlling the maximum temperatures reached and minimum times required for the sintering of the particles of lunar soil to solids essential for the formation of parts usable for construction of e.g. temporary habitats.
\end{abstract}

Keywords: ISRU, in-situ resource utilization, regolith, sintering based additive manufacturing
Volume 2 Issue 4 - 2018

\author{
Hartmut R Fischer \\ TNO Science and Industry, Netherlands
}

Correspondence: Hartmut R Fischer,TNO Science and Industry, Materials Performance, High Tech Campus 25, $5656 \mathrm{AE}$ Eindhoven, Netherlands, Email hartmut.fischer@tno.nl

Received: July 19, 2018 | Published: August 10, 2018

\section{Introduction}

Missions to mars will require a temporary base on the Moon consequently several options to create structures on the Moon using available lunar soil are discussed and under investigation. ${ }^{1-11}$ If insitu materials could be used on the Moon (such as regolith or regolith derived concrete), to build large civil engineering structures, then extensive amounts of mass launched from Earth could be avoided, making space exploration more economical and hence possible. ${ }^{12}$ For a mind-setting, this communication starts with a closer look to the environmental conditions present on the Moon and their effect on envisaged fabrication technology for structural constructive elements. The temperatures at the surface of the Moon ranges from $138^{\circ} \mathrm{C}$ as the sun reaches its highest point in the sky to $-153^{\circ} \mathrm{C}$ during the lunar night cycle. Any equipment designed to remain on the surface for extended periods of time, would have to deal with the enormous temperature swings which can be more than almost $300 \mathrm{~K}$ - not a trivial engineering challenge. The Moon's day/night cycle is about 27.3 Earth days long: 2 weeks of sunlight and 2 weeks of darkness. Because the Moon's rotation is locked to the Earth, its rate of rotation around the polar axis is exactly equal to the time it takes the Moon to go once around the Earth (also 27.3 days). Since the Moon has no magnetic field, it is subjected to a steady flux of galactic cosmic radiation (GCR) and low energy solar wind particles. The radiation levels are normally low enough (on the order of 1 to 2.5 particles per square $\mathrm{cm}$ per second) that people can carry on surface activities without any protection beyond what is offered by the space suits. However, during periods of high solar activity, it sometimes happens that the Sun ejects high energy particles and radiation in the direction of the Moon that can be lethal to anyone on the surface within just a few minutes of exposure.

Solar protons pose a significant risk to inadequately shielded crewmembers. Very large energetic particle events, which can cause acute radiation effects, occur at intervals of 7 to 10 years. Intermediate events, which can limit mission activities, occur several times each year. For nominal flares, build-up to peak radiation intensity occurs within a few hours or less. Monitoring of X-ray precursors may provide 30 minutes to one hour of additional warning. Additional, the hard vacuum on the surface of the Moon (about 2 orders of magnitude fewer particles per unit volume than low Earth orbit) also creates some problems. Many common plastics and rubber substances loose flexibility and become brittle due to out gassing in hard vacuum environments. Lunar dust may prove to be the most challenging and daunting of all the hazards facing future lunar explorers. ${ }^{13}$ Lunar dust is extremely fine, and extremely abrasive to machines, bearings, seals, etc. It is also pervasive. There is no where one can go to get away from lunar dust. As if that were not enough, the small size of the dust particles and their jagged nature makes them a serious health hazard to humans. Breathing in these particles is very likely to cause silicosis and even lung cancer. Micrometeorites can hit the Moon at speeds up to $100,000 \mathrm{~km} / \mathrm{h}$. Even a small particle the size of a grain of sand could puncture a space suit or the Apollo Lunar modules and cause enormous damage. Fortunately, these events are statistically rare. However, for long duration missions, there is a non-zero probability that the lunar habitat may get hit by one of these high energy micrometeorites. Therefore, it is necessary to provide some method of shielding.

The general technical demands for a suitable manufacturing process based on the at the Moon present circumstance are:

a. No or limited presence of liquids. Liquids form a problem on the Moon due to the vacuum. A direct phase transfer from liquid to gas will appear, instant boiling.

b. No or only limited consumables. The transport costs to the Moon are extreme high. The weight is a major issue but also the volume.

3D-Automated Additive Construction (AAC) could provide the solution for extra-terrestrial shelter (electromagnetic space radiation, thermal, micro-meteorites, dust storms, vacuum, fission power plant shielding, rocket blast eject at launch/landing, etc.) for human crews and robotic equipment on planetary surfaces. ${ }^{12}$ In view of the technical demands discussed and although demonstrations were recently achieved and reported concerning the earlier selected 
processes 3D-printing, Contour Crafting and sintering based additive manufacturing technologies, only the latter processes does not demand consumables and the use/application of liquids. Furthermore, other difficulties like handling of liquid binders under vacuum circumstances or potential freezing of materials in a wetmix based printing process can be avoided. ${ }^{11}$ A basic calculation showed that for sintering based technologies e.g. instead of a laser on the Moon the sun can be used. The focusing method can be by a lens, mirror array or Fresnel lenses ${ }^{14}$ as demonstrated by Kayser $\mathrm{M}^{15}$ and by NASA in a field test in $2010 .{ }^{16}$ Researchers tested microwave sintering with lunar regolith or simulant. Meek et al., ${ }^{17,18}$ noted that ilmenite $(\mathrm{FeTiO} 3)$ couples well with high frequency microwave resulting in densified basalts. The sintering of lunar simulant has been conducted under terrestrial conditions, i.e. normal temperatures, pressures and radiation as described in several publications as well as communicated e.g. by the Dutch national organization for Applied Research TNO at the 12th International Symposium on Materials in the Space Environment (ISMSE-12) 2012 and thus demonstrating the technical feasibility of this process. The lunar environment, especially the high vacuum present, is however crucial and should be considered for realistic sintering. Purpose of this communication is it to evaluate the feasibility of sintering of regolith under Moon (high vacuum) conditions.

\section{Properties and composition of Regolith}

Several geological samples from the Moon have been collected during the Apollo missions and subsequently analyzed. The Moon is composed of igneous rocks, which formed through the crystallization of silicate melts, along with breccias, which are created by meteorite impacts. Breccias are a mixture of rocks and regolith that are cemented together by a process of shock-metamorphism, induced by meteorite impacts. Most minerals within lunar rocks are silicates. The mineral composition of lunar basalts is around 50\% Pyroxenes, 20-30\% Plagioclase, and $0-20 \%$ Olivine by volume, lunar regolith contains additionally Ilmenite (ca. 15\%), and Anorthite (up to 20\%). ${ }^{19-21}$ Regolith is the layer of loose, unconsolidated rock of all sizes overlying bedrock. Overall the soil consists of crushed rocks mixed with glass particles. Nearly the entire lunar surface is covered with regolith, bedrock being exposed only on very steep-sided crater walls and the occasional lava channel. This regolith has been formed over the last 4.6 billion years by the impact of large and small meteoroids and the steady bombardment of micrometeoroids and solar and galactic charged particles breaking down surface rocks. The impact of micrometeoroids, sometimes travelling faster than $60,000 \mathrm{mph}$ $(96,000 \mathrm{~km} / \mathrm{h})$, generates enough heat to melt or partially vaporize dust particles. These melting and refreezing welds particles together into glassy, jagged-edged agglutinates, reminiscent of tektites found on Earth. The regolith is generally from 4 to 5 meters thick in mare areas and from 10 to 15 meters in the older highland regions. Below this true regolith is a region of blocky and fractured bedrock created by larger impacts, which are often referred to as the "megaregolith".

The uppermost layer of lunar regolith consists of particle sizes on the order of microns and contains rock chips, mineral fragments, impact and volcanic glasses and a peculiar component only found on the Moon called "agglutinates"; the glass content is between 10 and $20 \%$. Agglutinates are aggregates of mineral fragments held together with glass, are a major component of lunar soils and these agglutinates vary in content in lunar soil from $5-65 \mathrm{wt} \%$ with an average of around $25-30 \mathrm{wt} \%$. They are formed when a micrometeorite impact melts a small amount of soil. Agglutinitic glass is vesicular (holey) and is full of tiny blebs of metallic iron. Spherules are also a common component of lunar soils. These typically spherical (hence the name) droplets of glass can be formed volcanically, during "fire fountaining" when lava is thrown up and cools before it hits the ground; the Apollo 17 orange glass beads and the Apollo15 green glass beads are examples of this process. More commonly though, spherules are formed in impact, when melt is thrown up and cools before it falls back to the ground. Like agglutinates, impact spherules are found in a large array of sizes from sub-micron to several hundred microns (volcanic beads come in a narrower size range, averaging about 40 microns). Both agglutinates and impact spherules come in a wide array of compositions as well, dependent in large part on what material was melted to form them. ${ }^{19,20}$ The chemical composition of lunar soil is shown in Table 1.

Table I Chemical composition of lunar soil shown in abundance of oxides as lithology signature ${ }^{19,20}$

\begin{tabular}{ll}
\hline Compound & Concentration (\%) \\
\hline $\mathrm{SiO}_{2}$ & $42-48$ \\
$\mathrm{TiO}_{2}$ & $1-7$ \\
$\mathrm{Al}_{2} \mathrm{O}_{3}$ & $12-27$ \\
$\mathrm{FeO}$ & $4-18$ \\
$\mathrm{MgO}$ & $4-1 \mathrm{I}$ \\
$\mathrm{CaO}$ & $10-17$ \\
$\mathrm{Na}$ & $0.4-0.7$ \\
$\mathrm{~K}_{2} \mathrm{O}$ & $0.1-0.6$ \\
$\mathrm{MnO}$ & $0.1-0.2$ \\
$\mathrm{Cr}_{2} \mathrm{O}_{3}$ & $0.2-0.4$ \\
\hline
\end{tabular}

Broken down by element, about $43 \%$ of lunar soil is oxygen, $21 \%$ silicon, $13 \%$ iron, $8 \%$ calcium, $6 \%$ aluminum, $5 \%$ magnesium, and $4 \%$ other elements. However, composition varies considerably depending on the specific location; so this table is only an indication and does not represent the entire lunar surface. ${ }^{22}$ The particles of regolith (Moon dust) tend to be elliptical in shape but often have sharp points and edges. These grains have never been weathered by water or rolled by wind which would remove sharp edges. Particle size ranges from large rocks to gravel, sand, and down to dust with an average particle size of about $70 \mu \mathrm{m}$. This is too small to be visible with the human eye. The dust grains are defined to be any particles less than $100 \mu \mathrm{m}$ in diameter. Fine dust with particles less than $20 \mu \mathrm{m}$ can make up $10 \%$ to $20 \%$ of the mass of the regolith.

Although volatiles are stripped out from lunar minerals, some of them are still present, either adsorbed or included in particles (mostly in glass particles and/or agglutinates) created while parts of the Moon dust/surface were liquefied e.g. during an impact of a meteorite. Also, because the Moon has no atmosphere and the solar wind ions emitted from the sun at exceedingly high speeds (several hundred kilometers per second) are embedded or implanted into the surface material of the Moon. They do not penetrate very deep into a rock or mineral grain, only a few hundredths of a micrometer, so all the solar-wind-implanted atoms are at the very surface of lunar regolith grains. Meteorite impacts stir the surface regolith so that the upper few meters of regolith are rich in implanted ions of hydrogen and helium. The amount of solar-wind implanted ions is greater in the very finest material because the fine material has more surface 
area than the coarser material. When a micrometeorite strikes finegrained material at the surface, some of the material gets hot enough to melt and form the glass of an agglutinate. It also gets hot enough to liberate the solar-wind-implanted hydrogen and helium, causing bubbles in the glass. The main components analyzed in the samples collected during the Apollo and Luna missions contain $\mathrm{H}_{2}, \mathrm{He}, \mathrm{H}_{2} \mathrm{O}$, $\mathrm{N}_{2}, \mathrm{CO}, \mathrm{O}_{2}, \mathrm{H}_{2} \mathrm{~S}, \mathrm{CO}_{2}$ and $\mathrm{SO}_{2}$. The concentration of volatiles found in a sample of lunar regolith is presented in Table 2.

Table 2 Concentration of chemical elements forming volatiles in lunar regolith ${ }^{23-25}$

\begin{tabular}{ll}
\hline Element & Concentration (ppm) \\
\hline $\mathrm{H}$ & $0.1-211$ \\
$\mathrm{He}$ & $1-63$ \\
$\mathrm{~N}$ & $13-153$ \\
$\mathrm{C}$ & $10-280$ \\
$\mathrm{~S}$ & $20-1330$ \\
\hline
\end{tabular}

Typically, larger abundances of He (typically 20-80ppm) and other noble gases (Ne, Ar (both 1-10ppm), Kr, and Xe (both 1-3ppb)) are detected in the regolith and regolith breccias. Also, $\mathrm{H}_{2}$ contents in mature regolith are in the order of $120 \mathrm{ppm}$. The presence and comparatively large concentration of both $\mathrm{He}$ and $\mathrm{H}_{2}$ originates mainly from solar wind. Water $(30-450 \mathrm{ppm})$ may be present in the lunar regolith in several different reservoirs: ${ }^{26}$

a. $\mathrm{H}_{2} \mathrm{O}$ and/or $\mathrm{OH}$ in a thin millimeter layer on the most part of the lunar surface.

b. Structural bound water in the composition of some minerals in the form of $\mathrm{H}_{2} \mathrm{O}$ and or $\mathrm{OH}$

c. Water in the form of impurities and melt inclusions in minerals.

The carbon (all together $300-400 \mathrm{ppm}$ ) is mainly present as $\mathrm{CO}$ and $\mathrm{CO}_{2}$, other compounds are $\mathrm{CH}_{3} \mathrm{OH}, \mathrm{CH}_{4}$ and $\mathrm{C}_{2} \mathrm{H}_{4}$, the nitrogen (all together 150-250ppm) as $\mathrm{N}_{2}$ and $\mathrm{NH}_{3}$, and the sulfur (all together ca 20-1300ppm) as $\mathrm{SO}_{2}$ and $\mathrm{H}_{2} \mathrm{~S}$.

\section{Radiant heating and sintering of Regolith}

So far, several groups have demonstrated the feasibility of sintering of lunar regolith and regolith simulants..$^{7-10} \mathrm{~A}$ thermal analysis of the lunar regolith simulant Johnson Space Center 1A (JSC-1A) has revealed a basaltic glass transition temperature at $640^{\circ} \mathrm{C}$ and a major endothermic peak associated with the melting temperature at $1150^{\circ} \mathrm{C} .{ }^{9}$ This matches reasonably well with the data reported by Ray et al., ${ }^{27}$ which reported temperatures of $647^{\circ} \mathrm{C}$ and $1120^{\circ} \mathrm{C}$ respectively. In this study, glass (re) crystallization at $880^{\circ} \mathrm{C}$ was also found. Experiments in radiant heating of regolith simulant have been carried out by NASA Johnson Space Center and Lockheed Engineering \& Sciences Co. Results show that radiant heating can reproducibly sinter large, strong bricks in a fused silica mold. Fused silica was chosen for its combination of extremely low thermal conductivity and low density. Uniform bricks measuring $7.9 \times 5.5 \times 3.6 \mathrm{~cm}$ were produced by heating Minnesota Lunar Simulant 1 (MLS-1) Basalt for two hours at $1100^{\circ} \mathrm{C}$. Resulting bricks were crack free except for small expansion cracks near the top surface, with negligible reductions in volume and density. Larger bricks were produced from the simulant JSC-1. The sample was initially compacted using vibration for 5 minutes until reaching $2.45 \mathrm{~g} / \mathrm{cm}^{3}$, and then sintered for 2.5 hours at $1100^{\circ} \mathrm{C}$. A silica fabric liner was inserted between the simulant and the fused silica mold to prevent the brick from sintering to the mold..$^{28-30}$

That sintering may occur at temperatures around $1100^{\circ} \mathrm{C}$ has also been demonstrated on lunar regolith simulant MLS-1 by Pletka $\&$ Desai $^{27-29}$. Upon heating, thermal liquefaction of lunar regolith simulant starts (visible melting of the sample usually around $1200^{\circ} \mathrm{C}$ ). The sample became fluid and droplet shaped at temperatures of about $1250^{\circ} \mathrm{C} .{ }^{31}$ However, all these sintering studies were performed under ambient conditions and the feasibility of such a process under high vacuum has not been studied so far. Experiments concerning the thermal analysis and parallel release of gases generated from lunar samples are described by Gibson \& Johnson ${ }^{32}$. In this study, Apollo 11 and Apollo 12 samples were heated under vacuum to $1400^{\circ} \mathrm{C}$ with a rate of $4 \mathrm{~K} / \mathrm{min}$ and the released gaseous species were analyzed together with a determination of initial melting points. The melting points of both soil samples were between 1210 and $1135^{\circ} \mathrm{C}$, the weight loss while heating up to $1000^{\circ} \mathrm{C}$ between 0.14 and $0.2 \%$ (Figure 1) (Figure 2). ${ }^{32}$

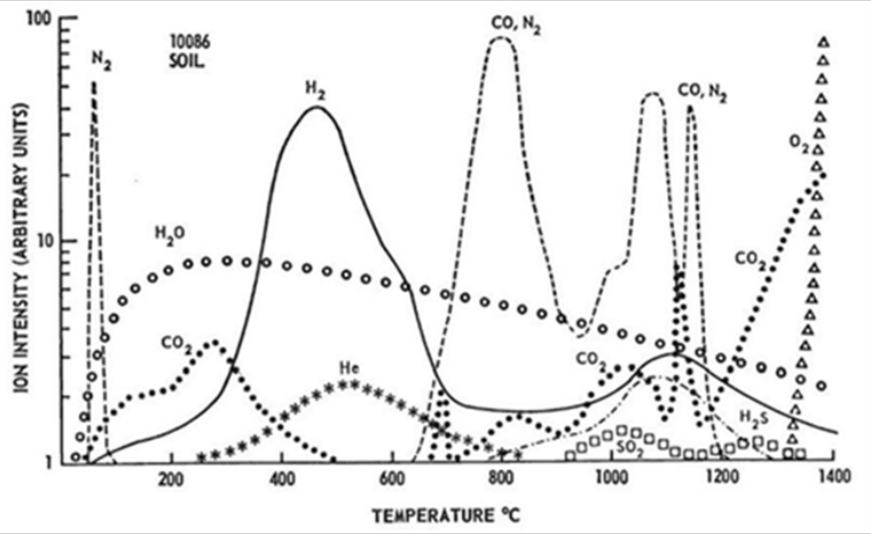

Figure I Gas release pattern for Apollo II soil 10086, I6. Sample weight $242.94 \mathrm{mg}$. Heating rate $4^{\circ} \mathrm{C} /$ minute.

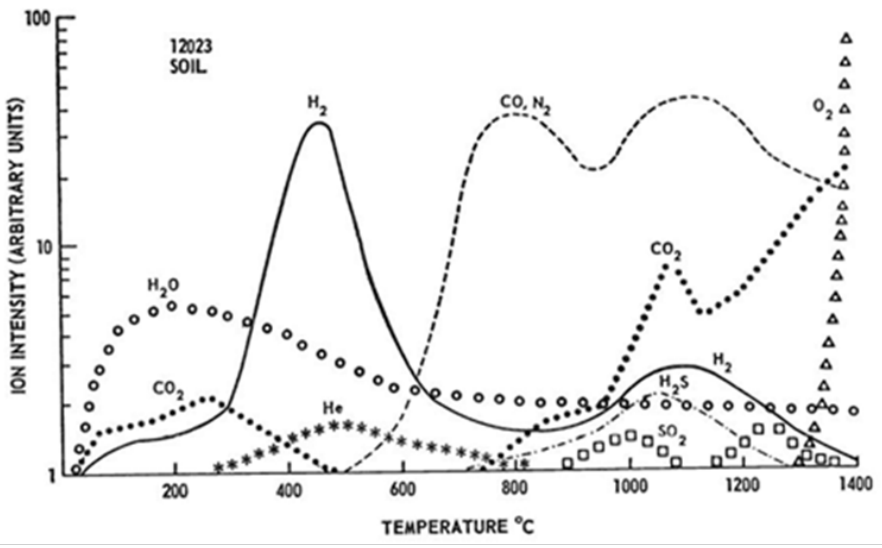

Figure 2 Gas release pattern for Apollo 12 soil 12023,9. Sample weight $208.50 \mathrm{mg}$. Heating rate $4^{\circ} \mathrm{C} /$ minute.

As already discussed, rock and mineral fragments at the lunar surface are exposed to the solar wind. However, the solar wind deposits many volatiles on the lunar surface besides hydrogen and helium such as nitrogen and carbon containing species. Over $90 \%$ of 
hydrogen and helium can be released from the regolith by heating from $200-700^{\circ} \mathrm{C}$. The largest quantities of nitrogen are released between $700-900^{\circ} \mathrm{C}$ and $1000-1200^{\circ} \mathrm{C}$. Less than $20 \%$ of nitrogen is released between $200-700^{\circ} \mathrm{C}$. Carbon is released as $\mathrm{CO}_{2}$ up to $600^{\circ} \mathrm{C}$; above $500^{\circ} \mathrm{C} \mathrm{CO}$ and $\mathrm{N}_{2}$ are released. At temperatures above $1200^{\circ} \mathrm{C} \mathrm{CO}$ dominates. Between $20-30 \%$ carbon is released between $200-700^{\circ} \mathrm{C}$. Regolith samples from mare regions of the Moon have been found to have higher concentrations of Sulphur. Very little $\mathrm{H}_{2} \mathrm{~S}$ is produced from $200-700^{\circ} \mathrm{C}$; the dominant temperature range for $\mathrm{H}_{2} \mathrm{~S}$ production is $900-1200^{\circ} \mathrm{C}$.

An analysis of the chemical composition of residues vs. percent of the initial mass evaporated shows that most of the iron is evaporated in the first $50 \%$ of mass loss. The other oxides steadily increase in this interval. After $50 \%$ mass loss, the refractory oxides $\mathrm{CaO}$, $\mathrm{Al}_{2} \mathrm{O}_{3}$, and $\mathrm{TiO}_{2}$ continue to increase and $\mathrm{MgO}$ and $\mathrm{SiO}_{2}$ evaporate. The evaporation loss is small at temperatures around $1500^{\circ} \mathrm{C}(6 \%$ in $96 \mathrm{hrs})$ and increases with melting temperature $\left(1800^{\circ} \mathrm{C} 18 \%\right.$ in $1 \mathrm{hr}){ }^{33}$ Melting experiments of materials with solar elemental proportions of iron, magnesium, silicon, titanium, calcium and aluminum oxide in vacuum performed at $1800^{\circ} \mathrm{C}$ and $2000^{\circ} \mathrm{C}$ showed, that the sequence of evaporation of the main constituents excluding oxygen is $\mathrm{Fe}>\mathrm{Si} \sim \mathrm{Mg}>\mathrm{Ti}$; $\mathrm{Ca}$ and $\mathrm{Al}$ remain unevaporated. ${ }^{32}$ Clearly heavy Fe evaporates first, followed by $\mathrm{Mg}$ and $\mathrm{Si}$. Similar is the condensation behavior of the different materials. In this case of course a condensation of the pure metals $\mathrm{Fe}$ and Ni occurs, since the evaporation is coupled with a split-off of oxygen. However, the temperatures are similar; hence the evaporation data represent a situation in or close to equilibrium. . $^{14,33,34}$

Investigations on the pyrolysis of lunar simulant MSL-1 show a similar behavior, during (vacuum) pyrolysis, a simultaneous reduction of metal oxides and a production of oxygen takes place. ${ }^{8}$ For this study, Fresnel type solar concentrators were used to generate the high temperatures needed and several different lunar minerals were studied including the lunar regolith simulant MLS-1. The measured vaporization temperature for MLS-1a under slightly reduced pressure $\left(10^{-1}\right.$ Torr $)$ was about $1800 \mathrm{~K}$ coupled with a generation of gaseous $\mathrm{SiO}, \mathrm{O}, \mathrm{O}_{2} \mathrm{Fe}$ and $\mathrm{Mg}$, this temperature was shifted to lower vales as the pressure was reduced. As reported earlier, ${ }^{4-7}$ the evaporation of Fe starts at a vacuum of $10^{-7} \mathrm{Torr}$ at around $1150 \mathrm{~K}$, followed by $\mathrm{SiO}$ and $\mathrm{Mg}$ at $1200 \mathrm{~K}$ and at higher temperatures by $\mathrm{Ca}$ and $\mathrm{Al}$. The weight loss has been measured and is reported in Table 3. Finally, in this study a pressure-temperature vaporization diagram could be constructed based on these data (Figure 3). ${ }^{14}$

Table 3 Results of a fresnel lens pyrolysis test on regolith simulant MLS- Ia ${ }^{14}$

\begin{tabular}{lllllll}
\hline Sample & $\begin{array}{l}\text { Approximate } \\
\text { Duration }(\mathrm{mins})\end{array}$ & $\begin{array}{l}\text { Flux }(\mathrm{W} / \\
\left.\mathrm{m}^{2}\right)\end{array}$ & $\begin{array}{l}\text { Initial Pressure } \\
(\text { Torr })\end{array}$ & $\begin{array}{l}\text { Testing Pressure } \\
(\text { Torr })\end{array}$ & MaxTemp $\left({ }^{\circ} \mathrm{C}\right)$ & Mass loss $(\%)$ \\
\hline MLS-I & 52 & 100 & $59.6 \times 10^{-2}$ & $1.4 \times 10^{-1}$ & 1474 & 10.1
\end{tabular}

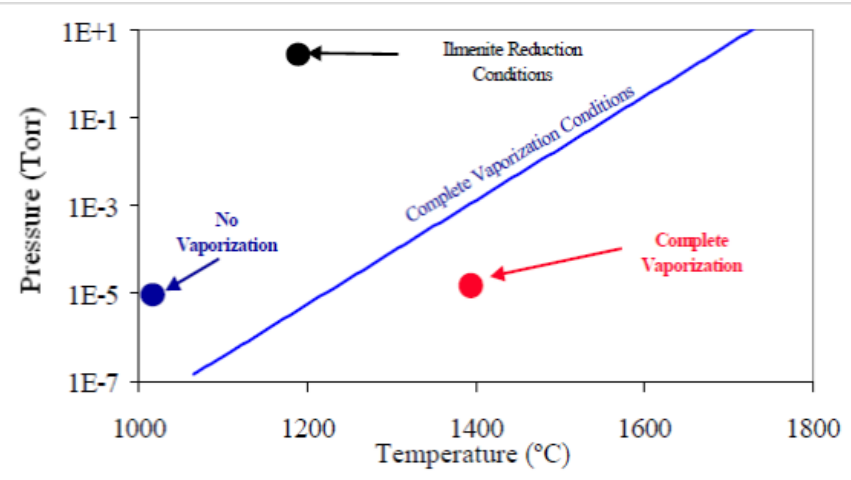

Figure 3 System pressure and temperature required to vaporize MLS-I. ${ }^{14}$

\section{Conclusion}

The In-situ Resource Utilization by using lunar soil to create structures on the Moon via sintering based additive manufacturing technology seems clearly possible and feasible. An application of Fresnel lenses or of a lens array as solar energy concentration system enables the realization of the temperatures needed for sintering of the particles of lunar dust/soil to solid brick like structures. Despite the thermal transient stresses and residual stresses of direct laser sintering of raw lunar regolith, ${ }^{7}$ initial experiments with the lunar simulants showed that the samples were successfully melted and formed into the desired parts with high geometrical accuracy. Regardless of the interesting results, however, direct laser sintering alone may not be an ideal fabrication method for a construction-scale object for following reasons:
1. Due to the existence and development of internal thermal stress concentrations resulting from the sintering and consequent shrinkage and cracking, the geometry and dimensions size of single parts and components manufacturable by sintering is limited.

2. Since the area and volume of one outpost would easily exceed $260 \mathrm{~m}^{2}$ and $2000 \mathrm{~m}^{3}$, the total energy required for construction of the structure protecting the volume of a practical outpost would be extremely high. However, solar sintering could be a suitable fabrication technique as solar energy is unlimited and readily available on the lunar surface.

3. Another noticeable drawback of direct laser sintering is that only a small volume of material can be thermally treated at a time, so such a process is rather slow and requires longer printing time for a wider area/volume.

An important point of attention is the generation of volatiles during heating of the solid particles to the sintering temperature and the possible pyrolysis of the material at temperatures higher than the temperatures required for sintering. This concerns not only the "buried" volatiles like water nitrogen, hydrogen etc. but also at higher temperatures produced oxygen due to decomposing of the minerals present in regolith. This process becomes dominant at higher temperatures and in vacuum. Therefore, a precisely tuned process for the sintering manufacturing controlling the maximum of temperatures (ca. $1100^{\circ} \mathrm{C}$ ) reached and times required for the sintering of the particles of lunar soil to solids is essential to enable the formation of parts usable for construction of e.g. temporary habitats. Only with such a precise process control is the production of constructive elements out of regolith using sintering based technologies with a guaranteed mechanical performance feasible. On the other side, there will be a 
benefit of sintering in vacuum instead of under atmospheric pressure, sintered structures will be more condensed and less porous due to the active removal of gas bubbles and hence more solid and stronger structures can be produced as recently demonstrated by Meurisse et al., ${ }^{35}$ In this study a decrease in porosity from ca. $23 \%$ to $13 \%$ causes an increase in modulus from 18 to $24 \mathrm{GPa}$ and of the compression strength from 98 to $152 \mathrm{MPa}$.

\section{Acknowledgements}

Figure 1 and 2 were reprinted from Lunar and Planetary Science Institute, Abstracts of the Lunar and Planetary Science Conference, volume 2 , Gibson, E. K., Jr.; Johnson, S. M., Thermal AnalysisInorganic Gas Release of Lunar Samples, 1351-1366 (1971) with permission of Elsevier and Figure 3 has being reproduced from Cardiff, E.H., Pomeroy, B.R., Banks, I.S., Benz, A., Vacuum pyrolysis and related ISRU techniques, (2007) AIP Conference Proceedings, 880, pp. 846-853, DOI: $10.1063 / 1.2437525$ with the permission of AIP Publishing.

\section{Conflict of interest}

The author declares that there is no conflict of interest.

\section{References}

1. Khoshnevis B, Bodiford MP, Burks KH, et al. Lunar contour crafting-A novel technique for ISRU-based habitat development. USA: $43^{\text {rd }}$ AIAA Aerospace Sciences Meeting and Exhibit-Meeting Papers; 2005. 7397 7409 p.

2. Hintze PE, Quintana S. Building a lunar or martian launch pad with in situ materials: Recent laboratory and field studies. Journal of Aerospace Engineering. 2013;26(1):134-142.

3. Bodiford MP, Fiske MR, McGregor W, et al. In situ resource-based lunar and martian habitat structures development at NASA/MSFC. Florida: AIAA- $1^{\text {st }}$ Space Exploration Conference: Continuing the Voyage of Discovery; 2005. 974-980 p.

4. Jakus AE, Koube KD, Geisendorfer NR, et al. Robust and Elastic Lunar and Martian Structures from 3D-Printed Regolith Inks. Scientific Reports. 2017;7:44931.

5. Ceccanti F, Dini E, De Kestelier X, et al. 3D printing technology for a moon outpost exploiting lunar soil. $61^{\text {st }}$ International Astronautical Congress; 2010. 8812-8820 p.

6. Cesaretti G, Dini E, De Kestelier X, et al. Building components for an outpost on the Lunar soil by means of a novel 3D printing technology. Acta Astronautica. 2014;93:430-450.

7. Balla VK, Roberson LB, O'Connor GW, et al. First demonstration on direct laser fabrication of lunar regolith parts. Rapid Prototyping Journal. 2012;18(6):451-457.

8. Goulas A, Friel RJ. 3D printing with moondust. Rapid Prototyping Journal. 2016;22(6):864-870.

9. Goulas A, Binner JGP, Harris RA, et al. Assessing extraterrestrial regolith material simulants for in-situ resource utilisation based 3D printing. Applied Materials Today. 2017;6:54-61.

10. Mueller RP, Sibille L, Hintze PE, et al. Additive Construction Using Basalt Regolith Fines. Earth and Space 2014: Engineering for Extreme Environments-Proceedings of the $14^{\text {th }}$ Biennial International Conference on Engineering, Science, Construction, and Operations in Challenging Environments; 2014. 394-403 p.

11. Lim S, Prabhu VL, Anand M, et al. Extra-terrestrial construction processes-Advancements, opportunities and challenges. Advances in Space Research. 2017;60(7):1413-1429.
12. Mueller RP, Howe S, Kochmann D, et al. Automated Additive Construction (AAC) for Earth and Space Using in Situ Resources. Earth and Space 2016: Engineering for Extreme Environments-Proceedings of the $15^{\text {th }}$ Biennial International Conference on Engineering, Science, Construction, and Operations in Challenging Environments; 2016. 354$377 \mathrm{p}$.

13. Park JS, Liu Y, Kihm KD, et al. Micro-Morphology and Toxicological Effects of Lundar Dyst. $37^{\text {th }}$ Annual Lunar and Planetary Science Conference; 2006. 2 p.

14. Cardiff EH, Pomeroy BR, Banks IS, et al. Vacuum Pyrolysis and Related ISRU Techniques. AIP Conference Proceedings. 2007;880(1):846-848.

15. Markus K. The solar sinter. Germany: Deezen; 2011.

16. Smith B, Nakamura T, Theiss R, et al. Results of Solar Sintering Experiment. Andover: The Space Resources Roundtable and the Planetary and Terrestrial Mining Sciences Symposium; 2010. 18 p.

17. Meek TT, Fayerweather LA, Godbole MJ, et al. Sintering lunar simulants using $2.45 \mathrm{GHz}$ radiation. In: Engineering, Construction, and Operations in Space: Proceedings of Space. New York: American Society of Civil Engineer; 1988.

18. Meek TT, Vaniman DT, Cocks FH, et al. Microwave processing of lunar materials: potential applications. In: Mendell WW (Ed.), Lunar Base and Space Activities of the $21^{\text {st }}$ Century. Houston: Lunar and Planetary Institution; 1985. 479-486 p.

19. Papike JJ, Simon SB, Laul JC. The lunar regolith: Chemistry, mineralogy, and petrology. Reviews of Geophysics. 1982;20(4):761-826.

20. Noble S. The Lunar Regolith. USA: NASA Lunar Petrographic Educational Thin Section Set; 2003. 39 p.

21. McKay DS, Heiken G, Basu A, et al. The Lunar Regolith. In: The Lunar Sourcebook, Heiken G H, Vaniman DT, French B M. eds. New York: Cambridge University Press; 1991. 285-356 p.

22. Taylor LA, Liu Y. Important considerations for lunar soil stimulants. Earth and Space 2010: Engineering, Science, Construction, and Operations in Challenging Environments. Honolulu, Hawaii: American Society of Civil Engineers; 2010. 13 p.

23. Jordan JL. Lunar Hydrogen and Other Volatiles. Huntsville: AIAA Space Programs and Technologies Conference; 1992. 7 p.

24. McCubbin FM, Kaaden KEV, Tartese R., et al. Magmatic volatiles (H, $\mathrm{C}, \mathrm{N}, \mathrm{F}, \mathrm{S}, \mathrm{Cl}$ ) in the lunar mantle, crust, and regolith: Abundances, distributions, processes, and reservoirs. American Mineralogist. 2015;100 (8-9):1668-1707.

25. Crotts APS. Lunar outgassing, transient phenomena, and the return to the moon. I. Existing Data. Astrophysical Journal. 2008;687(1):692-705.

26. Basilevsky AT, Abdrakhimov AM, Dorofeeva VA. Water and other volatiles on the moon: A review. Solar System Research. 2012;46(2):89107.

27. Ray CS, Reis ST, Sen S, et al. JSC-1A lunar soil simulant: Characterization, glass formation, and selected glass properties. Journal of Non-Crystalline Solids. 2010;356(44-49):2369-2374.

28. Pletka BJ. Processing of Lunar Basalt Materials. In: Resources of Near Earth Space, University of Arizona Press; 1993. 325-350 p.

29. Girdner K, Desai CS. Development of mechanical properties of structural materials from lunar stimulants by thermal liquefaction. Report to NASA-SERC, Tucson: University of Arizona; 1991.

30. Desai CS, Girdner K. Structural materials from lunar simulants through thermal liquefaction. Denver, Colorado: Proc. Eng. Construction and Operations in space, ASCE; 1992. 528-536 p.

31. Wang J, Davis AM, Clayton RN, et al. Chemical and isotopic fractionation 
during the evaporation of the $\mathrm{FeO}-\mathrm{MgO}-\mathrm{SiO}_{2}-\mathrm{CaO}-\mathrm{Al}_{2} \mathrm{O}_{3}-\mathrm{TiO}_{2}$ rare earth element melt system. Geochem Cosmochim Acta. 2001;65(3):479-494.

32. Gibson EK, Johnson SM. Thermal Analysis-Inorganic Gas Release of Lunar Samples. Abstracts of the Lunar and Planetary Science Conference. Lunar and Planetary Science Institute; 1971. 1351 p.

33. Wang J, Davis AM, Clayton RN, et al. Evaporation of single crystal forsterite: Evaporation kinetics, magnesium isotope fractionation, and implications of mass-dependent isotopic fractionation of a diffusioncontrolled reservoir. Geochim Cosmochim Acta. 1999;63(6):953-966.
34. Hashimoto A, Kumasawa M, Onuma N. Evaporation metamorphism of primitive dust material in the early solar nebula. Earth Planet Sci Lett. 1979;43(1):13-21.

35. Meurisse A, Beltzung JC, Kolbe M, et al. Influence of Mineral Composition on Sintering Lunar Regolith. Journal of Aerospace Engineering. 2017;30(4):1-2. 